\title{
Formação profissional no Brasil: revisão crítica, estágio atual e perspectivas
}

\author{
TARCISIO PATRICIO DE ARAUJO ${ }^{I}$ \\ e ROBERTO ALVES DE LIMA ${ }^{I I}$
}

\section{Introdução}

ISTEMAs e programas de qualificação profissional são estabelecidos em vinculação com o padrão tecnológico em que se encontra a economia de um país e é natural que assim seja. No caso brasileiro, considera-se - nos termos do presente artigo - a década de 1930 como marco temporal da análise realizada, quando a indústria se torna o principal impulsionador da economia brasileira; é nos anos 1930 que instrumentos de política governamental passam a incorporar explícita intencionalidade do Estado em defesa da industrialização brasileira.

Em termos históricos, experiências de qualificação profissional remontam ao Colégio das Fábricas (início do século XIX), aos liceus de artes e ofícios (segunda metade do mesmo século) e às escolas de aprendizes artífices (início do século XX) - quando o país se caracterizava, essencialmente, como primário-exportador. A indústria no Brasil tem grande impulso de 1870 até as primeiras décadas do século XX, mas só passaria a constituir "motor" do crescimento depois do "deslocamento do centro dinâmico" da economia, no início dos anos 1930 (apogeu da crise da economia cafeeira e deslocamento de capitais - dessa atividade essencialmente exportadora - para o setor industrial) (Furtado, 2009, cap.32). A década seguinte tem como pilar histórico da qualificação profissional de mão de obra industrial a criação do Senai (1942), instituição que permanece como o principal vetor de capacitação profissional para a indústria brasileira.

Ocorre que, nos termos do padrão tecnológico então vigente, um trabalhador alfabetizado e com escolaridade correspondente aos primeiros degraus da educação básica atendia às exigências técnicas do processo produtivo. No entanto, avanço industrial, processos de inovação tecnológica e ampliação de mercados passam a progressivamente demandar maior qualificação da força de trabalho.

Por outro lado, a rota de acelerada industrialização brasileira - à qual se associa um amplo conjunto de políticas públicas, incentivos e proteção - era parte de um modelo de desenvolvimento em que a expansão urbano-industrial ocupou espaço privilegiado, enquanto dois pilares básicos foram negligencia- 
dos: i) promoção de reforma fundiária no meio rural e políticas consistentes que garantissem o estabelecimento de uma agricultura de pequeno e médio portes, produtora de alimentos e geradora de empregos no campo; ii) criação de um sistema educacional não excludente, com perspectiva de longo prazo, que preparasse o país para o futuro. Consequências básicas da combinação da preeminência do urbano-industrial e de negligência no que respeita a reforma da estrutura fundiária rural e a educação são bem conhecidas: grande êxodo rural, sustentação de expressiva desigualdade funcional da riqueza e da distribuição da renda pessoal. O Estado - seja em períodos de governos democráticos, seja em época de regimes discricionários - logrou garantir a consolidação de um moderno aparelho industrial, mas não operou para romper a inércia da omissão e da negligência a respeito dessas duas questões sociais básicas (desigualdades de acesso a terra e a educação).

Contribuía para a funcionamento de tal modelo a acomodação do padrão de crescimento industrial e da matriz tecnológica à elástica oferta doméstica de mão de obra pouco qualificada, à pequena fração de mão de obra doméstica de maior qualificação e à importação de mão de obra estrangeira qualificada (principalmente via imigrantes vindos da Europa e do Japão). Por outro lado, enquanto um ambiente de maior competição no plano internacional não constituía "ameaça", o padrão de desigualdade distributiva de acesso a educação não foi significativamente alterado.

Foi necessário o país adentrar o mundo de maior competição internacional da era da globalização para - particularmente a partir dos anos 1990 - a questão educacional passar a ser destaque. Removido, ao final da primeira metade dessa década, o véu da alta inflação de três a quatro dígitos (iniciada em 1980) é que mais abrangentes políticas públicas de educação, emprego e renda entraram na agenda de políticas sociais, sendo objeto de programas de maior ambição, fundados em aportes consideráveis de recursos públicos.

No que compete a educação, o prejuízo representado pelo grande atraso do Brasil nessa área já era significativo. No mundo empresarial, escassez de mão de obra qualificada e implicações para a competitividade passaram a assumir maior dimensão. Mas o fator educacional já se tornara, no Brasil, crucial dimensão básica que - além de contribuir para ampliar e consolidar pobreza e desigualdade social - impõe limites a políticas de qualificação profissional, e afeta negativamente a produtividade do trabalho e a competitividade da economia. De fato, o respeito à correlação direta entre qualificação profissional e produtividade [do trabalho] tem como pressuposto básico um bom sistema educacional e, portanto, educação de boa qualidade. E, se um propósito-chave de um país é se desenvolver de forma sustentada e concorrer satisfatoriamente em um mundo competitivo, a experiência brasileira, em termos de educação (e qualificação profissional), tem sido desviante do padrão consolidado em nações comparáveis ao Brasil. ${ }^{1}$ 
Neste artigo, além de uma breve revisão crítica, fazemos (nos limites do espaço disponível) uma discussão sobre o presente estágio da qualificação profissional no Brasil - respeitada uma contextualização histórica -, argumentando que as perspectivas são preocupantes.

\section{Breve histórico}

É a partir dos anos 1930 (Nova República) e no decorrer dos anos 1940 que se traça novo caminho para o país, pelo qual indústria e mercado interno viriam a se tornar o motor da dinâmica econômica. Em tal contexto, educação profissional ganha nova e maior dimensão, assumindo contornos que lhe davam maior amplitude e se associavam a inovações tecnológicas vinculadas ao avanço industrial.

O vetor institucional de educação profissional era constituído pelas escolas profissionalizantes, que vieram a formar o que hoje se denomina Rede Federal de Educação Profissional e Tecnológica. Tais unidades passaram por diversas transformações, até a constituição dos Centros Federais de Educação Tecnológica (Cefet), atualmente denominados Institutos Federais de Educação (IFE).

O outro vetor de educação profissional, na área industrial, passou a ser o Senai - criado em 1942 -, primeira entidade formadora do que depois veio a ser o Sistema S.

Observe-se que a criação do Senai se dá no contexto das chamadas Leis Orgânicas do Ensino, às quais se associa o nome de Gustavo Capanema, então ministro da Educação (Camargos, 2011). Tratava-se de considerar educação como algo sistêmico, orgânico e integrado ao sistema social que se modernizava a partir do avanço industrial. $\mathrm{O}$ mercado de trabalho - materializado depois da abolição da escravatura, em 1888 - e consideravelmente expandido com acelerada implantação de estabelecimentos industriais desde o último quarto do século XIX até as primeiras décadas do século XX, ${ }^{2}$ passava por ampliação, com significativa incorporação de segmentos urbanos. A criação do Senai respondia, assim, a necessidades de atendimento de demandas de formação profissional para a indústria.

Trata-se, portanto, de dois vetores da formação profissional no Brasil, um dos quais (o Senai) financeiramente fundado em recursos parafiscais (percentual sobre o faturamento das empresas do setor industrial). O outro vetor - escolas técnicas federais - faz parte da rede escolar pública brasileira.

Tal modelo constituiu o pilar educacional-técnico-profissional associado ao período de industrialização por substituição de importações. Com a política industrial consolidada nos anos 1930-1940 (início da indústria de base no governo Vargas), grande expansão dessa indústria e do segmento de bens duráveis no período 1956-1960 (era JK), e momentos de expansão do período militar, o Brasil se tornou uma nação expressivamente industrial. De fato, no período usualmente considerado como representativo da chamada industrialização por substituição de importações (1930-1980) a economia brasileira cresce à média de 6,3\% ao 
ano, particularizando-se um crescimento médio anual de 7,3\% nos 34 anos do período 1947-1980, ou seja, a partir do imediato pós-Segunda Guerra Mundial. ${ }^{3}$

No decorrer dos anos 1980 e primeiros anos da década de 1990 - em que a agenda econômica é permeada por inflação, greves e reivindicações de reajustes salariais, desemprego, tentativas frustradas de estabilização - não se operam reformas econômicas ou institucionais de fundo, exceto o início de abertura comercial (1990-1992). Nessa década, deve-se destacar a criação em 1986 do seguro desemprego, ${ }^{4}$ política consolidada no capitalismo europeu desde o pós-Segunda Guerra Mundial.

Se grandes mudanças econômicas não são operadas nesse período, algumas reformas institucionais de certa profundidade ocorreram depois da promulgação da Constituição brasileira de 1988, o que permitiu ampliação do conjunto de políticas e programas sociais no Brasil ao longo das décadas de $1990 \mathrm{e}$ 2000: aposentadoria rural; Fundo de Amparo ao Trabalhador (FAT); Benefício de Prestação Continuada (BPC); Programa de Erradicação do Trabalho Infantil (Peti); bolsa escola e, ulteriormente, bolsa família - entre outros.

O FAT propiciou o que se considera o terceiro vetor da qualificação profissional: Plano Nacional de Qualificação Profissional (Planfor), iniciado em 1995, como parte do que veio a ser chamado de Sistema Público de Emprego e Renda, ${ }^{5}$ que englobava políticas ativas e políticas passivas para o mercado de trabalho (programas de geração de emprego e renda, qualificação profissional, intermediação de força de trabalho, seguro desemprego, esses dois últimos englobando o preexistente Sistema Nacional de Emprego - Sine).

Estabelecidas, nesta Introdução, as vertentes da formação profissional rede de educação técnica-profissional, Senai e as Políticas Públicas Nacionais de Formação ou Qualificação Profissional -, deve-se agora introduzir a dimensão básica que é crucial para a condução e a eficiência de tais programas: educação.

\section{Educação no Brasil:}

resultados que limitam programas de qualificação profissional

Vinculação entre educação, qualificação profissional e produtividade é algo contemplado na literatura econômica desde que o conhecimento em economia se apropria da importância da relação entre qualidade da força de trabalho, produtividade e lucro no capitalismo. Pode-se evocar o que já era explicitado pelo economista clássico Alfred Marshall (1890), no Princípios de Economia, obra em que se identificam vários argumentos consagrados na moderna literatura sobre economia do trabalho. Por exemplo, a distinção entre habilidades gerais e habilidades específicas e críticas ao ensino técnico da época, na Inglaterra, já eram elementos tratados por Marshall (ibidem).

Note-se que essa obra de Marshall foi concebida no contexto da segunda revolução industrial, quando já se aprofundavam demandas de respostas da força de trabalho a um mundo de importantes transformações tecnológicas, particularmente na indústria. 
O reconhecimento da importância da educação formal é evidente, por exemplo, no seguinte trecho dos Princípios de Economia:

É verdade que muitos tipos de trabalho podem ser desempenhados de forma igualmente eficiente, seja por um trabalhador não escolarizado ou por um escolarizado, e degraus mais altos da escala de educação são de pouca utilidade direta, exceto no caso de empregadores ou gerentes [ou outros cargos de chefia] e comparativamente menor número de artesãos. Mas uma boa educação traz grandes benefícios indiretos mesmo para o trabalhador comum; o faz mais inteligente, mais operador, prestativo e confiável no trabalho... é um importante meio para a produção de riqueza material. (Marshall, 1890, Livro I, cap.VI, seção IV.VI.15, $\mathbb{S} 5$ - tradução nossa $)^{6}$

Ademais, era preocupação de Marshall registrar que o quase exclusivismo da Inglaterra em termos de invenções na indústria, desde a primeira Revolução Industrial (a partir de 1750-1760), passava a conviver - no século XIX - com a "entrada de outras nações na corrida", referindo-se especificamente ao caso da Alemanha, considerada a difusão - nesse país - de conhecimento entre as camadas médias da sociedade e mesmo entre as "working classes" (ibidem, seção IV.VI.14). Esse economista clássico então antecipava a ideia de "competitividade nacional", um dos elementos centrais da corrente discussão sobre esse tema, no contexto da chamada globalização.

Essa referência histórica evidencia o atraso, no Brasil, da preocupação com políticas de reforço de competitividade da economia brasileira. A propósito, um pioneiro trabalho institucional com tal agenda data de $1993,{ }^{7}$ quando já se aprofundavam, no mundo, grandes mudanças tecnológicas e organizacionais datadas do início dos anos 1980, década em que o debate sobre economia, no Brasil, era - como já assinalado - permeado por desdobramentos econômicos, sociais e políticos da alta inflação e do baixo crescimento econômico. Tal registro serve como balizamento para as considerações, a seguir, sobre implicações - para o tema da competitividade - da questão educacional no Brasil.

O nível de qualificação da força de trabalho no país - avaliado pelo grau de escolaridade - revela que alguns limites enfrentados no mercado de trabalho decorrem do atraso educacional do Brasil, acumulado ao longo de décadas e décadas, e apenas minorado por meio de políticas educacionais implantadas, desde 1995, ao longo desses quase vinte anos.

Indicadores educacionais recentes revelam avanços, ao mesmo tempo que evidenciam significativa distância entre o Brasil e diversos países:

i) Conforme o IBGE (IBGE, 2012), ${ }^{8}$ considerado o estrato de estudantes de 18 a 24 anos de idade, em 2011 quase metade ainda não havia completado a trajetória da educação básica e ingressado na universidade, embora - entre 2001 e 2012 - a proporção dos que cursavam o Ensino Fundamental tenha se reduzido de $21 \%$ para $6 \%$ e a referente aos matriculados no Ensino Superior tenha se ampliado de $27 \%$ para $52 \%$, o que indica significativa redução do atraso escolar. 
Tal avanço, para ser efetivo, requer que a expansão das matrículas seja acompanhada de melhoria da qualidade do ensino - esse um aspecto que, no Brasil, requer maior atenção e ajustes.

ii) No entanto, ainda conforme IBGE (2012, Gráfico 3.5), a taxa de abandono escolar precoce da população de 18 a 24 anos, no Brasil, alcançava 26,6\% entre as mulheres e $37,9 \%$ entre os homens, proporções muito acima das prevalecentes em trinta países da Europa, e bastante próximas das referentes a Malta $(27,6 \%$ e $38,9 \%)$;

iii) Considerando-se o indicador de média de anos de estudo, ainda com foco no grupo de 18 a 24 anos de idade, entre 2001 e 2011 esse indicador, no país como um todo, passou de 7,9 para 9,6 - embora, segundo o IBGE, com persistência de desigualdades escolares entre estratos de rendimento mensal familiar per capita. No plano das regiões, o Nordeste (média de 8,8 anos de estudo, no grupo de pessoas com 18-24 anos de idade - em 2011) e o Norte (8,7 anos) têm as médias mais baixas, em contraste com Sudeste, Sul e Centro-Oeste - médias de dez anos nessas regiões.

iv) Tendo-se como foco o grupo populacional de 25 a 64 anos e 2011 como referência temporal, informações da Organização para a Cooperação e o Desenvolvimento Econômico (OCDE, 2013) dão conta de que no Brasil é de $43 \%$ a proporção de pessoas com Ensino Médio completo, em contraste com a média de 75\% nos países da OCDE; no que se refere ao nível de Ensino Superior completo, as proporções são de $12 \%$ no Brasil e $32 \%$ no âmbito da OCDE; ${ }^{9}$

v) Considerando-se agora pessoas com idade de 25 anos ou mais, no Brasil a média de anos de estudo evolui de 6,0 em 2001 para 7,3 em 2011; nas regiões, o Nordeste fica na pior situação, com evolução de 4,4 para 6,0 anos; no Sudeste, de 6,7 para 8,1 anos;

vi) Novamente focando-se o grupo de pessoas com idade a partir de 25 anos, indivíduos sem instrução e menos de um ano de estudo representam, em 2011 - sobre o total de pessoas nessa faixa etária - as proporções de 15,1\% no Brasil e 26,1\% no Nordeste. Aqueles com onze anos de estudo têm peso relativo de $23,9 \%$ no país e $21,0 \%$ na região. Os indivíduos com doze e mais anos de estudo constituem $15,5 \%$ no país e $10,1 \%$ no Nordeste;

vii) Adicionem-se informações que dão ainda maior dimensão ao problema educacional brasileiro: trata-se de resultados de pesquisa conduzida, em 2012, no âmbito do Movimento Todos pela Educação, envolvendo a realização - por cerca de 54 mil alunos do terceiro ano do Ensino Fundamental, antiga segunda série - de exames de avaliação, no país como um todo (2 a Avaliação Brasileira do Final do Ciclo de Alfabetização, "Prova ABC") ${ }^{10}$ (Tabela 1).

Tais resultados (referentes a crianças nos primeiros degraus da escala de escolaridade) revelam flagrante insuficiência daquilo que se documenta sobre avanços na educação brasileira, nos últimos vinte anos. No que se refere a escolas públicas, no país como um todo, 39,7\% dos alunos têm proficiência em leitura, 
a proporção no Nordeste alcançando $23,7 \%$; em matemática, as proporções são de $29,2 \%$ no Brasil e 13,6\% no Nordeste; em escrita, as respectivas proporções são $25,9 \%$ e 13,2\%. Quando considerados dados globais (escolas públicas e escolas privadas, conjuntamente), os indicadores melhoram, mas ficam entre $30 \% \mathrm{e}$ $45 \%$ no Brasil, e na faixa de $19 \%$ a $30 \%$ no Nordeste. Portanto, tais indicadores revelam a urgência e a dimensão da tarefa de redução do atraso educacional brasileiro. Ademais, torna-se evidente que - em termos qualitativos - a situação é mais grave que a percebida a partir de indicadores quantitativos.

Tabela 1 - Brasil e Região Nordeste. Proporção de alunos (\%), do $3^{\circ}$ ano (antiga segunda série) do Ensino Fundamental, com proficiência em leitura, matemática e escrita - 2012

\begin{tabular}{c|c|c|c|c}
\hline \multirow{2}{*}{} & \multicolumn{2}{|c|}{ Escolas Públicas } & \multicolumn{2}{c}{$\begin{array}{c}\text { Todo o sistema } \\
\text { (público + privado) }\end{array}$} \\
\cline { 2 - 5 } & Brasil & NE & Brasil & NE \\
\hline Leitura & 39,7 & 23,7 & 44,5 & 30,7 \\
\hline Matemática & 29,2 & 13,6 & 33,3 & 18,1 \\
\hline Escrita & 25,9 & 13,2 & 30,1 & 18,9 \\
\hline
\end{tabular}

Fonte: Movimento Todos pela Educação. $2^{\text {a }}$ Avaliação Brasileira do Final do Ciclo de Alfabetização, "Prova ABC" 2012.

Nota: 600 municípios pesquisados, 1.185 escolas (públicas e privadas), 54 mil alunos.

Quando se consideram indicadores que põem o país no contexto internacional, o quadro atual revela a desconfortável posição do Brasil. De fato, conforme resultados do PISA 2012, ${ }^{11}$ o desempenho dos estudantes brasileiros em Leitura piorou em relação a 2009, embora tenha ocorrido avanço em Matemática (com manutenção do mesmo resultado em Ciências). Quase metade $(49,0 \%)$ dos alunos brasileiros não alcança o nível 2 de desempenho conforme escala em que o nível 6 representa o máximo. Na prática, isso significa que tais alunos são incapazes ou têm grande dificuldade de interpretar o conteúdo de um texto, e de estabelecer vinculações entre pontos do texto lido.

Dos números destacados nesta seção conclui-se que apesar da melhoria de indicadores educacionais (quantitativos) no Brasil e nas macrorregiões, o quadro atual ainda constitui um grande desafio, com o Nordeste permanecendo na pior situação, no âmbito das macrorregiões. É evidente a grande dimensão da tarefa de qualificação profissional, a partir de um insatisfatório patamar de escolaridade, de trabalhadores que constituem importante estrato da força de trabalho cujo potencial de produtividade é alvo estratégico em políticas de reforço da competitividade da economia brasileira.

Nesse contexto, resta, para políticas de formação profissional, a tarefa de requalificar força de trabalho que, na maioria dos casos, não tem a base escolar 
mínima para apreender adequadamente uma qualificação profissional específica e se adequar às exigências de conhecimento global, capacidade de raciocínio lógico, entre outros requisitos de um padrão tecnológico mais exigente. Disso decorre ser natural o país estar enfrentando problemas de escassez de força de trabalho qualificada, e segmentos de atividade econômica enfrentem problemas de competitividade - em particular empresas vinculadas a exportação e aqueles que concorrem, no mercado interno, com importações. Note-se que tais circunstâncias têm significativa dimensão, apesar da operação de um amplo sistema de formação profissional, temática a que é dedicada a seção seguinte.

\section{Contextualização da política pública de formação profissional no Brasil}

É depois da estabilização de preços alcançada desde a implementação da moeda Real, em 1994, que - a partir de 1995 - começa a operar o sistema público nacional de emprego e renda, com o Planfor imediatamente absorvendo apreciável volume de recursos ${ }^{12}$ e ganhando grande visibilidade na sociedade, por conta da participação de $\mathrm{ONG}$, sindicatos e outras instituições da sociedade civil como agentes executores de programas de qualificação profissional ou como agentes de "controle social".

O Planfor logo cedo passou a operar em ambiente de desemprego elevado. De fato, após os dois primeiros anos desde a instituição da moeda Real - curto período em que o mercado de trabalho se beneficiou de impactos positivos nos campos distributivo e de crescimento econômico (5,3\% em 1994; 4,4\% em $1995)^{13}$-, a economia brasileira passou a sofrer com uma sucessão de crises externas da economia internacional, o que - no plano interno - provocou restrições ao crescimento derivadas da elevada taxa de juros básica da economia. A valorização da moeda (decorrente da chamada "âncora cambial", um dos pilares da política macroeconômica) era outro fator gerador de desemprego, contribuindo para o quadro adverso do mercado de trabalho na segunda metade dos anos 1990 .

A economia manteve padrão de crescimento abaixo da média histórica do país e do potencial da estrutura produtiva brasileira, havendo então expectativa de elevação da taxa de desemprego. Em tal ambiente, a consolidação de um "sistema público de emprego" serviria como um contraponto à insuficiente geração de postos de trabalho.

Tal expectativa se fundava em um diagnóstico pelo qual se atribuía ao mercado de trabalho a origem básica do aumento dos níveis de desemprego, o que redundava em se privilegiar, em termos analíticos, o lado da oferta de trabalho (insuficiente qualificação da força de trabalho face às transformações tecnológicas e organizacionais das empresas).

Por outro lado, um novo patamar de elevação da taxa de desemprego particularmente a partir da segunda metade dos anos 1990 - contribuiu para agravar um quadro em que se combinavam alto nível de desocupação (com 
aumento da importância do setor informal), inflação alta, baixo crescimento da economia. Desemprego e "precarização" das relações de trabalho eram termos-chave em boa parte da literatura econômica da época.

Foi, portanto, em um ambiente de grande "déficit social" que se iniciou, no Brasil, em 1995, a rota de consolidação de um sistema público de emprego, tendo-se como carro-chefe um ambicioso programa de qualificação de mão de obra, visando reduzir a "exclusão social", aumentar níveis de produtividade e, na prática, representar uma espécie de "redenção do desemprego". ${ }^{14}$

Em período mais recente - desde 2004-2008, quando o PIB nacional cresceu a $4,7 \%$ ao ano (mais que o dobro da taxa verificada nos anos de 1995 a 2003 : $2,2 \%$ ao ano ${ }^{15}$ ) -, embora a economia não desfrute de um padrão de crescimento sustentado, o ambiente econômico é menos adverso. De fato, a taxa média de desocupação da força de trabalho é bem menor.

A partir de 2009, com o advento da crise econômica mundial iniciada em 2007-2008 nos Estados Unidos, além de fatores internos de esgotamento de impactos da expansão da demanda agregada (ampliação do crédito, manutenção da política de aumento real do salário mínimo inaugurada em maio de 1995, expansão de transferências federais de renda - principalmente dos programas Benefício de Prestação Continuada e Bolsa Família), a economia brasileira também começa a sentir efeitos de um processo de desaceleração, mesmo enfrentando relativamente baixas taxas de desemprego.

A explicação para a manutenção de baixas taxas de desemprego, apesar da desaceleração da atividade econômica como um todo, tem duas vertentes:

- uma, oriunda da perspectiva analítica da demografia, decorre da redução do crescimento da oferta de trabalho - consequência do processo de transição demográfica (vertiginosa queda, entre 1970 e 2010, da taxa de fecundidade da população - de 6,0 filhos para menos de dois ( 1,9 - abaixo da taxa de reposição de 2,1 filhos por mãe) -, o que tem espelho no envelhecimento da população e se expressa, no mercado de trabalho, pela redução do peso relativo da população em idade de trabalhar (a partir de 10 anos, até os 64 anos); ${ }^{16}$

- outra vertente estaria no lado da demanda por trabalho: apesar da desaceleração da atividade econômica, haveria um crescimento da população ocupada, tendo como principais propulsores atividades vinculadas ao comércio, aos serviços e à construção civil, o que responderia significativamente pela absorção de mão de obra e o aumento da renda média do trabalho (Jatobá, 2013).

Nesse novo contexto, em cada unidade da federação brasileira, a configuração atual da política pública nacional de qualificação profissional (Plano Nacional de Qualificação (PNQ)) tem linhas programáticas que mantêm as políticas estaduais de qualificação (Planteq), via convênios entre o Ministério do Trabalho e Emprego (MTE) e os governos estaduais (secretarias de trabalho), e ampliam a participação de governos municipais. Ademais, é promovida a expan- 
são de unidades de educação técnica profissional (os IFPE, nova denominação para as escolas técnicas de educação profissional) e criado (em 2011) o Programa Nacional de Acesso ao Ensino Técnico e Emprego (Pronatec), do Ministério da Educação - que busca "oferecer cursos de educação profissional a estudantes, trabalhadores diversos, pessoas com deficiência e beneficiários dos programas federais de transferência de renda". Trata-se de programa que - utilizando a ampla Rede Federal de Educação Profissional, Científica e Tecnológica e fazendo parcerias com unidades do Sistema $S$ - busca expandir a oferta de educação profissional e tecnológica, de forma articulada com a elevação da escolaridade do trabalhador. A exemplo de outros programas de qualificação profissional, esse também contempla, prioritariamente, a dimensão social de inclusão de segmentos menos favorecidos da população. De modo similar ao que ocorre no sistema Planfor-PNQ, a vertente social do Pronatec, com prioridade para famílias inscritas no Cadastro Único, tende a ampliar a importância de cursos de menor carga horária, dirigidos a segmentos sociais cujas maiores chances de inserção no mercado de trabalho repousam em ocupações no setor informal da economia (diversas atividades de trabalho por conta própria) $;{ }^{17}$ trata-se de algo bem diferente de formação profissional estrito senso, envolvendo cursos técnicos (carga horária mínima de 1.200 horas) dirigidos a pessoas com escolaridade mínima de segundo grau.

\section{Qualificação profissional: o desafio da avaliação}

Foi mencionado, na seção anterior, que o sistema público de capacitação profissional, instituído no país em 1995 e submetido a alguma reformulação em 2003 (mantida a mesma essencialidade), não foi associado - apesar da grande magnitude dos recursos monetários absorvidos - a procedimentos satisfatórios de avaliação de resultados, a exemplo do que se vem fazendo, desde 1995, no segmento de educação, com a instituição de práticas regulares de avaliação (Exame Nacional do Ensino Médio (Enem); Exame Nacional de Desempenho de Estudantes (Enade); Prova Brasil).

Abordam-se-se, nesta seção, esforços pontuais de avaliação de programas de capacitação profissional, tendo-se como base estudos realizados no âmbito do estado de Pernambuco: a) o primeiro estudo é uma pesquisa de iniciativa do Senai, via contratação de uma empresa privada para avaliação de cursos dessa instituição; b) o segundo, um estudo conduzido pelos próprios autores, realizado no âmbito da Universidade Federal de Pernambuco (UFPE).

O primeiro concerne a avaliação de capacitação profissional envolvendo quase todos os segmentos da indústria de transformação de Pernambuco ${ }^{18} \mathrm{e}$ cobrindo questões relativas a mão de obra (aspectos pertinentes a qualificação profissional e demanda por capacitação profissional).

Uma síntese dos resultados que podem ser generalizados para todos os segmentos pesquisados - focando-se o núcleo da problemática abordada neste artigo - aponta para o seguinte quadro: a) falta de profissionais qualificados 
como principal dificuldade para o recrutamento de pessoal; b) falta ou insuficiência de experiência na função é mencionada como problema; no entanto, é significativo o fato de $45,0 \%$ dos representantes de empresas entrevistados terem assinalado carência de conhecimento tecnológico adequado entre trabalhadores com experiência; c) a escolaridade da força de trabalho seria, na maioria dos casos, incompatível com o perfil da ocupação a ser preenchida, as razões sendo atribuídas a deficiências do ensino básico e a insuficiência ou falta de conhecimento tecnológico.

O segundo estudo, realizado em 2007-2008, contempla egressos de cursos de qualificação profissional (Planteq 2005) realizados pela UFPE em 20052006. Os principais cursos eram dirigidos a ocupações em atividades de comércio e prestação de serviços (recepcionista, qualidade no atendimento, cerimonial de eventos, auxiliar administrativo, operador de caixa); e a cursos para pedreiro, soldador, mecânico, marceneiro, operador de trator e empilhadeira, mecânico de automóveis; cursos de informática e de língua estrangeira.

O estudo contemplou a situação ocupacional de egressos, mais de um ano depois de esses terem frequentado os cursos, fazendo-se contraposição entre a situação "atual" do egresso - no momento da pesquisa - em termos de inserção no mercado de trabalho e o status ocupacional do egresso imediatamente antes da inscrição. De um total de 430 egressos, restaram 330 - subtraídos 95 não entrevistados por diversas razões (mudança de endereço, endereço não localizado, recusa, entre outros motivos); e cinco indivíduos que declararam não haver frequentado os cursos para os quais se inscreveram.

Note-se que o contexto da realização do estudo era de desemprego elevado, a despeito do melhor desempenho da economia brasileira como um todo. ${ }^{19}$ Destaquem-se os seguintes resultados:

i) cerca de $75 \%$ dos indivíduos contemplados na pesquisa pertenciam à faixa etária dos 17-25 anos. Em termos de educação, 51\% tinham escolaridade de Segundo Grau completo, cerca de 30\% com Segundo Grau incompleto, e o restante dividido quase igualmente entre Primeiro Grau (completo ou incompleto) e nível universitário (completo ou incompleto).

ii) $90,0 \%$ dos 330 egressos contemplados na análise se declaravam desempregados - em busca de uma ocupação no mercado de trabalho - quando se inscreveram e iniciaram os cursos. Apenas 33 indivíduos estavam então exercendo alguma ocupação, dos quais 25 no setor formal;

iii) $86,2 \%$ (256) dos 297 egressos que estavam desempregados imediatamente antes da inscrição nos cursos permaneciam em situação de desemprego no momento da pesquisa direta, mais de doze meses depois. Os 41 indivíduos restantes estavam ocupados: 27 em ocupações temporárias no setor formal; $13 \mathrm{em}$ ocupações no setor informal; um fazia estágio;

iv) quanto aos 41 indivíduos que - no período considerado - transitaram da condição de desocupados para ocupados, a respectiva ocupação não guardava 
relação com o curso específico frequentado, tal desvinculação sendo expressamente admitida por cada um dos entrevistados. Assim, elementos explicativos da mudança ocupacional observada (não ocupados para ocupados) teriam relação com, entre outros possíveis fatores, a própria formação dos indivíduos, ou seja, com a qualificação que já tinham e não com eventual aporte adicional de qualificação que cada curso possa ter eventualmente propiciado.

Para todo o grupo pesquisado, portanto, o que veio a ocorrer em termos de situação ocupacional - no período de referência da análise - se vinculava a fatores associados ao próprio mercado de trabalho e a características individuais e circunstâncias em que cada indivíduo se situava. Ou seja, a capacitação recebida se revelou neutra em termos de mudança ocupacional. Resultados similares também foram encontrados em outros estudos, a exemplo de pesquisa realizada por professores da Universidade de São Paulo (USP) (Fernandes, 2000).

\section{Considerações finais}

Contrastando com os números que são divulgados sobre a qualificação profissional no país, tanto por parte do Sistema S quanto do Sistema Público de formação profissional, os resultados sinalizam que o mercado de trabalho se ressente de trabalhadores qualificados e que há restrições ao funcionamento da formação escolar básica como requisito para inserção do indivíduo na população ocupada. De fato, mesmo se dispondo de um amplo sistema de qualificação profissional, é vocalizada - no setor empresarial privado - a insuficiência de mão de obra qualificada.

Ocorre que o usual e necessário treinamento empreendido no próprio ambiente da unidade produtiva - a exemplo do que presentemente ocorre na implantação de polos industriais no Nordeste, assim como em outras regiões torna-se alternativa primordial utilizada pelas empresas, em busca de atender as necessidades da economia. Mesmo assim, tais iniciativas de qualificação incluem cursos de nivelamento de conhecimentos básicos - evidência da insuficiência do sistema educacional.

Torna-se claro ser inadiável uma redefinição do sistema de formação profissional da força de trabalho no país, ao mesmo tempo que se avance na superação de deficiências da educação básica. No entanto, não se percebem ações concretas dirigidas a tais propósitos, o que condena o país a conviver, no médio prazo, com restrições a importantes avanços em produtividade do trabalho e competitividade da economia.

Se tais diretrizes não forem intensivamente respeitadas, eventual elevação da taxa de crescimento da economia continuará sendo restringida por insuficiência de força de trabalho qualificada - cenário aparentemente mais provável. 


\section{Notas}

1 Evidente que a temática aqui discutida concerne a uma de várias implicações da educação para uma sociedade, tanto em termos econômicos quanto no que se refere a aspectos sociais e políticos (desigualdade, cidadania, bem-estar, consolidação de instituições democráticas, entre outros) que afetam as condições de vida de uma população.

2 Conforme o Inquérito Industrial de 1907 - primeiro levantamento geral da atividade industrial no Brasil, realizado naquele ano por uma organização privada, o Centro Industrial do Brasil, a pedido do governo federal (Versiani; Suzigan, 1990) - o total de operários industriais, considerados os principais produtos dessa atividade, montava a 151.841 pessoas, incluídas 51.992 do segmento de fiação e tecelagem (ibidem), uma das primeiras atividades industriais estabelecidas no Brasil.

3 Cálculos a partir de dados extraídos de <www.ipeadata.gov.br>.

$4 \mathrm{Na}$ época, com cobertura muito limitada; hoje, é acessível para qualquer trabalhador inserido no segmento formal da economia.

5 A partir de 2003, o Planfor é rebatizado como Plano Nacional de Qualificação (PNQ) e o sistema público de emprego passa a ser Sistema Público de Emprego, Trabalho e Renda (SPETR). Algumas alterações foram realizadas, mas na essência o sistema permaneceu o mesmo.

6 No original: "It is true that there are many kinds of work which can be done as efficiently by an uneducated as by an educated workman: and that the higher branches of education are of little direct use except to employers and foremen and a comparatively small number of artisans. But a good education confers great indirect benefits even on the ordinary workman. It stimulates his mental activity; it fosters in him a habit of wise inquisitiveness: it makes him more intelligent, more ready, more trustworthy in his ordinary work; it raises the tone of his life in working hours and out of working hours; it is thus an important means towards the production of material wealth..."

7 Ver MCT-FINEP-PADCT (1993), um estudo sobre competitividade da indústria brasileira, sob a coordenação geral de Luciano Coutinho (Unicamp) e João Carlos Ferraz (UFRJ).

8 Dados de Pesquisa Nacional por Amostra de Domicílios (Pnad) - conforme IBGE (2012) e IBGE (2013).

9 Informações referentes ao ano 2011.

10 Conforme <http://www.todospelaeducacao.org.br/comunicacao-e-midia/noticias/ 27340/445- dos-alunos-do-3-ano-tem-proficiencia-adequada-em-leitura/>

11 Programme for International Student Assessment (Pisa) [Programa Internacional de Avaliação de Estudantes]. O Pisa é desenvolvido e coordenado pela Organização para Cooperação e Desenvolvimento Econômico (OCDE), cada país participante tendo uma coordenação nacional. No Brasil, o Instituto Nacional de Estudos e Pesquisas Educacionais Anísio Teixeira (Inep) desempenha esse papel. Trata-se de avaliação que permite comparação entre países, aplicada entre estudantes na faixa etária dos quinze anos, idade que - na maioria dos países - corresponde à conclusão da escolaridade básica (Ensino Fundamental completo, no caso brasileiro).

12 Em quinze anos de funcionamento da política pública brasileira de qualificação profissional (1995 a 2009), os recursos utilizados montaram a mais de R\$ 5 bilhões, a preços de dezembro de 1994 (ver Ramos, 2009, p.30 - Tabela 1). 
13 Conforme dados do IPEA (<www.ipea.gov.br/ipeadata>), cuja fonte básica é o IBGE.

14 Ver, por exemplo: Ramos (2009); Araújo; Lima (2009); Fernandes et al. (2000).

15 Conforme IPEA (<www.ipea.gov.br/ipeadata).

16 A respeito, ver, por exemplo: Jatobá (2013) e Cariello (2013). Note-se, por outro lado, que a expansão da oferta de trabalho por indivíduos de 65 anos ou mais parece ser um aspecto que se acentua no Brasil pelos menos nas duas últimas décadas.

17 Note-se que o Pronatec tem grande amplitude, provendo cursos técnicos com um mínimo de 1.200 horas, dirigidos a qualificação profissional propriamente dita. Entretanto, é necessário que tal programa seja submetido a avaliações sistemáticas, o que também se aplica aos programas do Senai e de outras entidades do Sistema $S$ - um imperativo da execução de políticas sociais. Os resultados até aqui alcançados, como se argumenta neste artigo, demandam o respeito a tal princípio.

18 Ver Senai-PE (2013). O único segmento não contemplado foi o de minerais não metálicos.

19 A taxa de desemprego aberto na Região Metropolitana de Recife, no ano 2006 - conforme a Pesquisa Mensal de Emprego (IBGE) - atingiu o valor de pico de 16,5\% nos meses de março e abril e média anual de $13,3 \%$. Note-se que o nível de desocupação da força de trabalho estava em queda, nos principais centros metropolitanos, em linha com a trajetória de maior nível de crescimento da economia brasileira no período 2004-2008.

\section{Referências}

ARAÚJO, T. P. de; LIMA, R. A. de. Public employment policies as tools for the reduction of poverty and inequality in Brazil. In: CIMADAMORE, A. et al. (Ed.) The Poverty of the State. Reconsidering the role of the state in the struggle against global poverty. Buenos Aires: Consejo Latinoamericano de Ciencias Sociales - Clacso, 2005. (Clacso Books, Clacso-Crop Series).

Olhares sobre a recente política de qualificação profissional no Brasil: controle social e reorientação. In: JUNIOR MACAMBIRA; CARLEIAL, L. M. da F. (Org.) Emprego, trabalho e politicas públicas. Fortaleza: Banco do Nordeste, Instituto de Desenvolvimento do Trabalho, 2009. p.77-121.

CAMARGOS, F. P. Conjuntura histórica da fundação do SENAI e educação profissional no Brasil. Iniciação Científica, Curitiba, n.3, 2011.

CARIELLO, R. O enigma e o demógrafo. Revista Piani, n.80, p.42-8. maio 2013.

FERNANDES, R.; MENEZES-FILHO, N. A.; ZYLBERSTAJN, H. Avaliando o PLANFOR: o Programa do Sindicato dos Metalúrgicos de São Paulo. São Paulo: Universidade de São Paulo, 2000.

FURTADO, C. Formação econômica do Brasil. Edição comemorativa 50 anos. Org. Rosa Freire d'Aguiar Furtado. São Paulo: Cia. das Letras, 2009.

IBGE - INSTITUTO BRASILEIRO DE GEOGRAFIA E ESTATÍSTICA. Síntese de Indicadores Sociais - Uma análise das condições de vida da população brasileira 2012. Ministério do Planejamento, Orçamento e Gestão. IBGE. Diretoria de Pesquisas. Co- 
ordenação de População e Indicadores Sociais. Estudos e Pesquisas, Informação Demográfica e Socioeconômica, 29. Rio de Janeiro, 2012.

IBGE - INSTITUTO BRASILEIRO DE GEOGRAFIA E ESTATÍSTICA. Síntese de Indicadores Sociais - Uma análise das condições de vida da população brasileira 2013. Ministério do Planejamento, Orçamento e Gestão. IBGE. Diretoria de Pesquisas. Coordenação de População e Indicadores Sociais. Estudos e Pesquisas, Informação Demográfica e Socioeconômica, 32. Rio de Janeiro, 2013.

IPEA - INSTITUTO DE PESQUISA ECONÔMICA APLICADA. Radar: tecnologia, produção e comércio exterior. Diretoria de Estudos e Políticas Setoriais, de Inovação, Regulação e Infraestrutura, n.23, dez. 2012.

JATOBÁ, J. Crescimento e desemprego. Revista Algomais, Recife, ano 7, n.82, jan. 2013. LIMA, R. A de; ARAUJO, T. P. de. A UFPE no espaço da política pública de qualificação profissional: potencial e resultados. Recife: Universidade Federal de Pernambuco, Centro de Ciências Sociais Aplicadas, Departamento de Economia. 2009.

MARSHALL, A. The Principles of Economics. 1890. Book IV, Chapter VI ("Industrial Training”). Disponível em: <http://www.econlib.org/library/Marshall/marP.html>.

MCT - MINISTÉRIO DA CIÊNCIA E TECNOLOGIA; FINEP - FINANCIADORA DE ESTUDOS E PROJETOS; PADCT - PROGRAMA DE APOIO AO DESENVOLVIMENTO CIENTÍFICO E TECNOLÓGICO. Estudo da competitividade da indústria brasileira. Qualificação, treinamento da mão de obra e competitividade: relações de trabalho e mecanismos de proteção social. Nota técnica temática do Bloco "Condicionantes Sociais da Competitividade" (por Azuete Fogaça e Claudio L. Salm, Unicamp). IE/Unicamp - IEI/UFRJ - FDC - Funcex. Campinas, 1993. Coordenação Geral do estudo: Luciano Coutinho (Universidade Estadual de Campinas, Instituto de Economia) e João Carlos Ferraz (Universidade Federal do Rio de Janeiro, Instituto de Economia Industrial).

. Plano Nacional de Qualificação 2003-2007: resolução n. 333. Brasília, DF, 2003.

Plano Nacional de Qualificação 2003-2007: orientações para a elaboração dos Projetos Especiais de Qualificação - Proesq. Brasília, DF, 2004.

OECD. Education at a Glance 2012: OECD Indicators, OECD Publishing. Disponível em: <http://dx.doi.org/10.1787/eag-2012-en>. Acesso em: 11 set. 2012.

Education at a Glance 2013: OECD Indicators, OECD Publishing. Disponível em: <http://dx.doi.org/10.1787/eag-2013-en>. Acesso em: 25 jun. 2013.

RAMOS, C. A. Auge e decadência das políticas de emprego no Brasil. In: JUNIOR MACAMBIRA; CARLEIAL, L. M. da F. (Org.) Emprego, trabalho e politicas públicas. Fortaleza: Banco do Nordeste do Brasil, Instituto de Desenvolvimento do Trabalho, 2009. p.29-48.

SENAI-PE - SERVIÇO NACIONAL DE APRENDIZAGEM INDUSTRIAL. Departamento Regional de Pernambuco. Pesquisa de Identificação das Demandas por Capacitação Profissional e Serviços Técnicos e Tecnológicos no Estado de Pernambuco. Recife, 2013. (Relatório de pesquisa).

VERSIANI, F. R. Imigrantes, trabalho qualificado e industrialização: Rio e São Paulo no início do século. Revista de Economia Política, v.13, n.4 (52), out.-dez. 1993. 
VERSIANI, F.; SUZIGAN, W. O processo brasileiro de industrialização: uma visão geral. Brasília: Universidade de Brasília, Departamento de Economia, 1990. (Série Textos Didáticos, 10).

RESUMO - O artigo apresenta uma revisão crítica da experiência de qualificação profissional no Brasil, examinado o presente estágio da política de formação profissional, e são consideradas perspectivas. $\mathrm{O}$ atual padrão educacional restringe $\mathrm{o}$ avanço da formação profissional da força de trabalho e os números da qualificação profissional no país se contrapõem aos resultados obtidos. Escassez de trabalhado qualificado e restrições ao funcionamento da formação escolar básica como requisito para adequada inserção ocupacional do indivíduo são questões-chave. Busca efetiva de avanços na qualidade da educação e redefinição do sistema de formação profissional da força de trabalho condicionam metas de elevação da taxa de crescimento da economia. Infelizmente, não se percebem ações concretas dirigidas a tais propósitos, o que condena o país a conviver, no médio prazo, com importantes restrições a avanços em produtividade do trabalho e em competitividade da economia; mantido tal panorama, eventual elevação da taxa de crescimento da economia continuará sendo restringida pela insuficiência de força de trabalho qualificada - cenário aparentemente mais provável.

PALAVRAS-CHAVE: Formação profissional, Avaliação de políticas, Competitividade, Educação, Senai (Serviço Nacional de Aprendizagem Industrial).

ABSTRACT - The authors perform a critical review of Brazilian labour force professional training, analyse the current training system's stage and take into consideration a prospective view. Brazil's current educational standard prevents labour training programmes from reaching satisfactory improvement over time; that being so, the actual qualitative results of such programmes contradict the country's published data on professional training. Also, qualified labour remains scarce and restrictions to an adequate functioning of education as means of fostering occupational insertion of labour force are key questions. Improvements in education quality and redesigning of training policies condition economic growth goals; adversely, there is no evidence of effective actions aimed at such objectives, which instead makes the country bound to face - on a medium term basis - restrictions to productivity and competitiveness gains. Should such a panorama prevail, improvement in economic growth rate will remain limited by scarcity of qualified labour.

KErWORDs: Professional qualification, Policies evaluation, Competitiveness, Education, Senai (National System of Industrial Training).

Tarcisio Patricio de Aranjo é professor da Universidade Federal de Pernambuco (UFPE); Ph.D pela University College London, UK. @ - tparaujo@gmail.com

Roberto Alves de Lima é professor da Universidade Federal de Pernambuco (UFPE), e doutor pela mesma Universidade. @-alroberto@gmail.com

Recebido em 16.6.2014 e aceito em 2.7.2014.

I, II Universidade Federal de Pernambuco. Recife/PE, Brasil. 